\title{
A NEW DECISION SUPPORT SYSTEM FOR SUPPLIER SELECTION USING BOOLEAN ALGEBRA
}

\author{
Nasina Jigeesh \\ Department of Operations \& Systems, IBS Hyderabad, IFHE University, Dontanapalli, \\ Shankerpalli Road, Hyderabad - 501203, India.
}

\begin{abstract}
For organizations operating with number of products/services and number of suppliers, to select the right supplier meeting all their requirements will be a challenging job. Such organizations need a good decision support system to evaluate the suppliers effectively. Several decision support systems have been reported to deal with complex selection process to decide the right supplier. Many mathematical models have also been developed. This paper presents a new method, named as Bit Decision Making (BDM) method, which treats such complex system of decision making as a collection and sequence of reasonable number of meaningful and manageable sub-systems by identifying and processing the relevant decision criteria in each sub-system. Help of Boolean logic and Boolean algebra is taken to assign binary digit values to the selection criteria and generate mathematical equations that correlate the inputs to the output at each stage of decision making. Each sub-system with its own mathematical model has been treated as a standardized decision sub-system for that phase of making decision in evaluating suppliers. The sequence and connectivity of the sub-systems along with their outputs finally lead to selection of the best supplier. A real-world case of evaluation of information technology (IT) tenders has been dealt with for application of the proposed method. The paper discusses in detail the theory, methodology, application and features of the new method.
\end{abstract}

\section{KEYWORDS}

Decision support systems, Supplier selection, Information systems, Boolean algebra, Supply chain management, Multi criteria decision making, Decision models

\section{INTRODUCTION}

Decision-making environments formulate helpful mathematical models (linear programming, nonlinear programming, etc.) with objective functions that specify the estimated consequences of any combinations of decisions (Hillier and Lieberman, 2001). The descriptive theory of problem solving and decision making is centrally concerned with how people cut problems down to size: how they apply approximate, heuristic techniques to handle complexity that cannot be handled exactly. Operations research and artificial intelligence are forging powerful new computational tools; at the same time, a new body of mathematical theory is evolving around the topic of computational complexity (Simon, 1986).

Several qualitative and quantitative decision making methods have been reported (Kepner and Tregoe, 1981; Saaty and Kearns, 1985; Saaty, 1990; Edwards and Barron, 1994; Hooks, 1994; Folger and LeBlanc, 1995; Saaty, 1995; Clemen, 1996; Goodwin and Wright, 1998; Hammond et al, 1999; France et al, 2002; Sharma et al, 2004; Harris, 2006; Miah and Huth, 2011). Pros and Cons analysis is a qualitative comparison method in which good things (pros) and bad things (cons) are identified about each alternative and this method is suitable for simple decisions with few alternatives ( 2 to 4 ) and few discriminating criteria ( 1 to 5 ) of approximately equal value. It requires no mathematical skill and can be implemented rapidly. Kepner-Tregoe (K-T) decision

DOI : 10.5121/ijmpict.2014.5302 
analysis is a quantitative comparison method in which a team of experts numerically score criteria and alternatives based on individual judgements (assessments). Some practical techniques applied to simple or complex decisions include T-Chart, PMI (Plus, Minus and Interesting), Buriden's Ass, Measured Criteria and Decision Matrix or Weighted Decision Table (Harris, 2006).

France et al (2002) details the use of a multiple-objective decision-making methodology and an integrative geographical information system-based decision-making tool developed to help watershed councils prioritize and evaluate restoration activities at the watershed level. Sharma et al (2004) presents a lexicographic goal programming (LGP) model for management decisionmaking in petroleum refinery industry for distribution of oil to the various depots.

The objective of supplier selection is to select appropriate suppliers that can provide faster delivery, reduced cost and improved quality in order to increase corporate competitiveness and additionally searching for those suppliers and continuously assessing their performance are critical supply chain activities (Yang and Chen, 2006).

Linear-weighting (LW) models were used to evaluate potential suppliers using several equally weighted factors, and then allow the desion-maker to choose the supplier with the highest total score (Timmerman, 1986). Mathematical-programming (MP) models can also be used to select the suppliers by creating an objective function to be maximized (for example, profit) or minimized (for example, costs), that is, performing optimization, by varying the values of the variables in that objective function. According to De Boer et al (1998) and Ghodsypour and O'Brien (1998), LW models do not include quantitative factors, whereas the MP models have the disadvantage of not including qualitative factors in selecting suppliers.

Analytic hierarchy process (AHP) is a quantitative comparison method used to select a preferred alternative by using pair-wise comparisons of the alternatives based on their relative performance against the criteria. The basis of this technique is that humans are more capable of making relative judgements than absolute judgements. AHP technique was used in designing evaluation models for various applications (Yang and Chen 2006, Ghodsypour and O'Brien 1998). Ghodsypour and O'Brien (1998) proposed an integrated AHP and linear programming model as a decision support system for selecting supplier. Yang and Chen (2006) proposed an integrated evaluation model by combining the AHP and grey relational analysis (GRA) to select the suppliers. Multi-attribute utility theory (MAUT) is a quantitative comparison method used to combine dissimilar measurement of costs, risks, and benefits, along with individual and stakeholder preferences, into high-level aggregated preferences. Min (1994) used the multiattribute utility approach to deal with the problem of selection of international suppliers using the criteria described as financial, quality, risks, service, partnerships, cultural and communication, and trade restrictions. Paulus and Riemann (2013) proposed to use a company-specific valuecreation for the cloud-affinity and the cloud-usability of a business process in public sector. They considered specific challenges of addressing processes in cloud services. They also considered all relevant security criteria alongside the process lifecycle and formulates the process-security management requirements derived from each single life-cycle phase.

In this paper, a new decision making system, named as Bit Decision Making (BDM) method has been proposed to simplify the decision process in complex systems. BDM method is based on both qualitative and quantitative factors in assigning and processing the scores of suppliers to select the right supplier. In this method, a complex system is divided into reasonable number of sub-systems and each sub-system is described with some criteria items based on its special characteristics and objectives and scores of either ' 1 ' or ' 0 ' (binary digits) are assigned to those criteria items. By applying Boolean logic and simple Boolean algebra, the method automates the decision process in each sub-system and the filtered quality entities pass on to the next sub- 
system in a hierarchical order to be awarded scores based on the special criteria items adopted therein. This process continues till the single final entity is selected. The proposed method is unique in methodology when compared to existing decision making methods. This paper elaborates the method to strengthen its scope of application. As an example, the BDM method has been applied to the case of evaluation of IT tenders covering different stages of tender evaluation, namely, 'Invitation to tender', 'Business strengths', "Technical', 'Financial quotation' and 'Final evaluation'. The proposed method is user-friendly in terms of its simplicity to input either ' 1 ' or ' 0 ' based on the policy framed by the user/organization. The result of set of input binary digits for each alternative will also be worked out by a suitable binary relationship between the inputs and the probable output.

\section{CASE STUDY}

The present study proposes an evaluation model as a decision support system to select a supplier. To demonstrate the model, a real-world case study was carried out during 1997-2000 relating to evaluation of IT tender bids received by a government technical consulting agency, ABS Ltd. (to maintain confidentiality, the name of the organization is herewith referred to as ABS Ltd.) for computerization of different government organizations in a Southern Indian state. That was the time when India, especially the said state government was very aggressive in initiating and implementing various prestigious IT projects to enable the whole state fully computerize its administration. Many state government organizations were directed to approach ABS for its consultancy for computerization of whole or partial organizational activities by procuring hardware, office automation, various software packages and development of relevant software solution(s). ABS is a wholly owned state government corporation focusing on e-Governance, by providing consultancy, procurement services and implementation support to the government entities for their Information and Communications Technology initiatives. ABS evolved different evaluation methods to select the right suppliers for the right work requested by any government organization. The case study deals with the role of ABS in calling for IT tender bids and the way ABS evaluated them and finalized the right vendor/supplier to do the specified IT job proposed. To maintain confidentiality, the mostly adopted common process of evaluation of IT tender bids for state government organizations and various stages of such evaluation process along with evaluation criteria has been highlighted in this paper without mentioning the name of a specific state government department. But, the needful description of the evaluation process is presented without any gaps or misunderstandings.

When any state government organization approaches ABS for selecting supplier for a specific IT activity, ABS first performs a preliminary investigation of requirements and availability of funds of the user organization. When the project is feasible, ABS notifies the request for proposal (RFP) and invites the tender bids as an open tender process. Different suppliers/vendors from all over India will submit both the technical and financial bids separately. The bids received after the due date will be rejected. To evaluate the accepted tender bids and select the right supplier out of them, ABS follows several phases of evaluation with specific criteria issues in each phase. The phases include Preliminary evaluation phase, Business strengths evaluation phase, Technical (Demonstration) evaluation phase, Financial Quotation evaluation phase and Final evaluation phase.

Preliminary evaluation phase starts with the activity of checking the bids whether they have satisfied the mandatory requirements of the bid process, in this case, making appropriate earned money deposit (EMD) and providing evidence of specified business (information technology) line. Here, the 'bidder' means the vendor/supplier organization, which sends its authorized people as their representative(s) to participate in the bidding process. For a bidder, if any of these two criteria items is assigned negative score, that bidder will be disqualified and eliminated 
from further evaluation process. The bidders qualified in the preliminary phase will be evaluated in the second phase, that is, Business strengths evaluation phase, in terms of their past performance in the business. For this purpose, the business performance for the last three financial years, technical staff and available infrastructure will be treated as evaluation criteria issues. In this case, lot of assumptions could be made to pass or fail those bidders who failed to generate profits in any one or two of the past three financial years based on right analysis and analogy. The help of scores gained in the remaining two criteria items, namely, technical staff and infrastructure would also be taken to evaluate the bidder. Of course, the bidder who ran in losses in the last three consecutive financial years would be naturally disqualified.

For the technical evaluation phase, the bidders passed in the second phase would be authorized to visit the client organization for a short duration to develop a prototype application for a specific activity based on their preliminary study on the organization's requirements. The prototype application developed by the bidders will be evaluated in terms of their understanding and analysis of requirements, technical skills to develop the application accordingly and expressing and presenting the problem and solution in a clear and convincing manner. All these issues would be treated as the evaluation criteria issues in this phase, based on which the bidder would assign scores appropriately. The bidders who successfully pass this phase would be promoted to the next phase, that is, Financial Quotations evaluation phase. Like in most organizations, ABS opens the financial quotations submitted by the bidders at the beginning of the tender bids along with the technical bid. The financial bids of the bidders who passed the previous phase would be opened in the presence of all the bidders and the estimated cost quoted by them for the specified work would be announced openly. ABS used to consider two major issues in this phase, namely, the score obtained by a bidder in the previous technical phase and the cost quoted by that bidder in the financial quotations phase and if the bidder is found to be technically sound among all the rest, but quoted highest price, that bidder might be negotiated over the price or further services or both. If the bidder is rigid on the price, there may be chances to consult another bidder who obtained next better score in the technical evaluation. Therefore, based on the score of technical evaluation phase and the price quote and tendency for further negotiations on price and services, the bidders would be evaluated in this final phase. A single successful bidder would be finalized in this phase and the work order would be placed on that bidder.

Following the objectives and evaluation criteria of each phase, the BDM method involves development of a truth table by listing the criteria items and assigning Binary values ( 0 or 1$)$ to each criteria item for each vendor/supplier and at the end of each phase, a mathematical model by correlating the output with the inputs will be generated. The mathematical model thus created for each phase of evaluation would be treated as an evaluation standard to evaluate bidders for that particular phase.

In order to automate the application of this method, a Microsoft Excel spreadsheet has been developed to automatically calculate the outputs for each vendor as per the input scores assigned for every phase of evaluation. This methodology can be customizable for other industries also with simple modifications. The method stresses the need of effective integration of specialized knowledge and experience of the evaluators with the objectives and policies of the organization in dividing the complex decision-making system into reasonable number of meaningful and manageable sub-systems, identifying the right decision criteria or attributes with proper guidelines and assumptions to assign the binary scores for different entities in each sub-system and completing the process with final wholesome decision. 


\section{BIT DECISION MAKING (BDM) METHOD}

A disciplined and transparent decision-making process employing credible evaluation methods will provide: structure to approach complex problems; rationale for decisions; consistency in the decision making process; objectivity; documented assumptions, criteria, and values used to make decisions; and decisions that are repeatable, reviewable, revisable, and easy to understand (Baker et al, 2001).

The main objectives of BDM method are to (i) breakdown the complex decision system into as many smaller and manageable sub-systems as possible and (ii) apply Boolean logic and Boolean algebra to the decision process in each such sub-system. A complex system will be broken down into reasonable number of meaningful and manageable small sub-systems and each sub-system consists of some relevant decision criteria. Each criterion is assigned a value of either ' 1 ' 'or ' 0 ', that is, a binary number, to represent either 'yes' or 'no', either 'true' or 'false', either 'correct' or 'incorrect', 'either 'on' or 'off', etc. The group of possible alternative values of a criterion forms a pattern of binary values. Hence, different patterns of binary digits are possible from all the relevant criteria of a particular sub-system. The set of binary values of all the criteria will result an output, which will represent the decision to be made in that particular case. Similarly, the output is also treated as a binary digit, which is decided by the decision-maker.

In order to make the whole decision system consisting of binary digits and each variable equated to a bit value (either ' 1 ' or ' 0 '), the output derived from two or more input values is limited only to a single bit, which is the last bit, by suppressing the carrier, if any. For example, if an output is a result of addition of two input bit values, the addition $1+0$ results ' 1 ', but $1+1$ results only ' 0 ' (the carrier ' 1 ' is suppressed) to limit the output value to a single bit. Thus, the Boolean logic represented by a binary digit is implemented in the BDM method for both input and output values.

It is the user (decision maker) that decides to assign either ' 1 ' or ' 0 ' to the selected decision criterion based on the analogy and the logic the user weighs, adopts and treats correct. The decision maker may either be an individual expert or a group of experts. After assigning binary digits to different criteria in a sub-system, the user has to again decide the result of their output, i.e., either to assign ' 1 ' or ' 0 ' based on the strategy under implementation. This method of assigning binary values to inputs and outputs generates different sets of combinations in different sub-systems and each combination of inputs has an output. The analogy and logic that is followed for a sub-system should be treated as a standard for that system and a standard mathematical equation can be generated using Boolean algebra by correlating the inputs to their respective output. Any change in the analogy results changes in the assignment of binary values to the inputs and the outputs and thereby leads to changes in the correlation equation. Thus, a sub-system with fixed mathematical model (correlation equation) can be treated as a standardized decision system. Figure 1 represents the process of decision making and mathematical modeling in BDM method. 


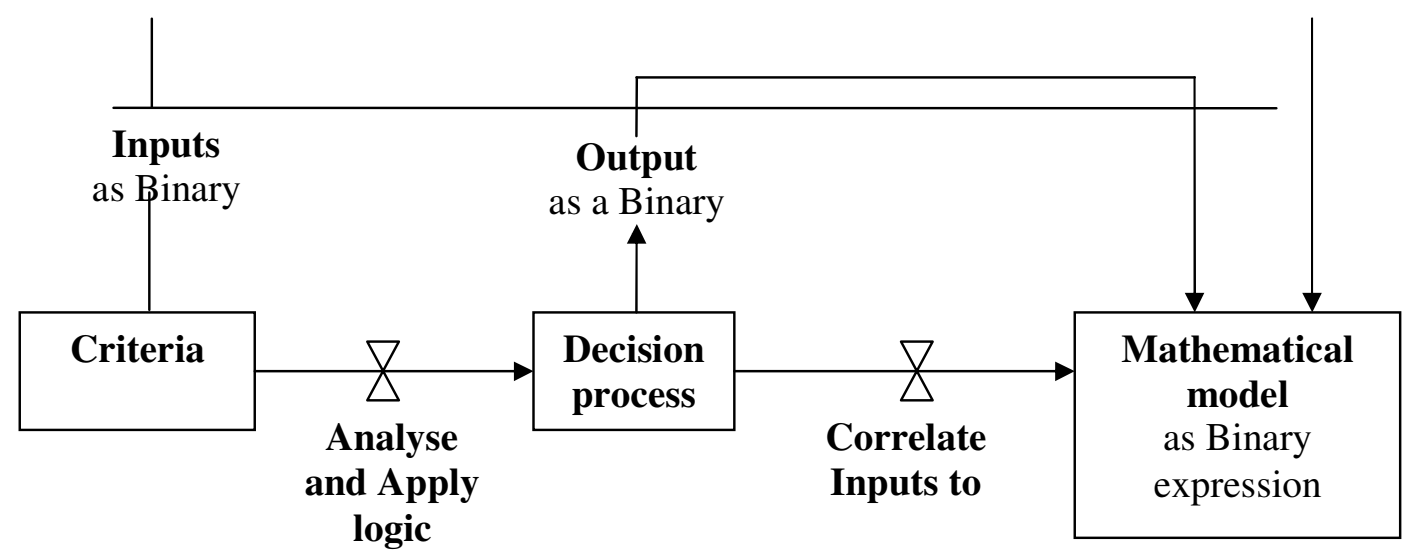

Figure 1. BDM evaluation model

BDM method can be applied to any simple or complex decision systems. In the case of complex systems, the system should be divided into a reasonable number of independent, meaningful and manageable sub-systems and each such sub-system is treated with the above procedure and a unique mathematical correlation equation can be derived for it. This needs thorough study and analysis of the total system, its break-down into different sub-systems and the various decision criteria possible in each sub-system.

The method is having both quantitative and qualitative dimensions. Quantitative is in the sense that Boolean values are assigned to each criteria item and processed in the form of mathematical equations. Qualitative is in the sense of identifying the right and potential criteria items and assigning values appropriately in each sub-system of evaluation.

\section{PROCESS OF EVALUATION OF INFORMATION TECHNOLOGY (IT) TENDER BIDS}

Clients are able to get a minimum price by putting out the contract to competitive bid and advertising an invitation for bid that lists customer requirements usually results in low bids [7,9]. The IT tender bids cover development of an IT product or service, sub-contracting part or total of project work, purchase of software, hardware, stationery, related tools and peripherals, etc. The IT tender process generally consists of many stages like (1) Invitation to tender, (2) Preliminary phase of evaluation (evaluation of mandatory requirements), (3) Evaluation of business strengths of bidders, (4) Evaluation of technical strengths of bidders, (5) Evaluation of financial quotations submitted by bidders and (6) Finalization of successful bidder.

The 'invitation to tender' documents the customer requirements, needs, terms and conditions and also the eligibility of the bidder in different aspects like resources, business and technical capabilities. Responding to the invitation to tender openly, in general, many suppliers will submit their tender bids.

Tender bid normally consists of mandatory and desired requirements of the contractor. If any tender bid does not meet the mandatory requirements, that proposal will be immediately rejected. Examples for mandatory requirements are payment of earnest money deposit (EMD) for participation in tender, matching business of the bidder, etc. The evaluation criteria involved in 
this preliminary phase of tender process are to check whether the bidder has paid the EMD amount and whether the bidder is in the same business line to handle the proposed work.

The bids, that pass in the preliminary evaluation phase, are eligible for the next stages of evaluation, namely, Business strengths, Technical, Financial quotation and Final evaluations. The number of phases of evaluation process can be modified depending on the user's criteria, choices, resources, requirements and vision.

In the business strengths evaluation phase, evaluation is focused on the business turnover of the bidder, for example, the business turnover in the last three financial years, that is, whether the business is running in profit or loss. Evaluation of other business strengths like availability of resources (both manpower and infrastructure), etc. may also be considered. For this purpose, the bidders or their representatives may be interviewed and their development sites even be visited.

The technical (demonstration) phase may include the evaluation criteria such as supplier's level of analysis of the requirements of user, development skills, and presentation skills. For this evaluation phase, the bidders who are successful in the previous phase will be invited to give demonstration on their study and analysis of user requirements, any prototype application developed, etc.

Evaluation of financial quotations depends mainly on the price quoted by the bidder in the financial bid, which is submitted in a separate sealed cover along with the tender bid. This phase may also include another decision criterion, the bidder's flexibility for negotiations on price and service. For this evaluation phase, the bidders qualified in the technical phase will be considered and their financial bids opened in the presence of those bidders.

The last phase, called the Finalization of successful bidder, evaluates the performance of the bidders in the technical phase in comparison with their financial quotes and the subsequent negotiations held on price and services and finally selects the successful bidder to award the work or purchase order.

When all the above phases of evaluation are managed properly, the task of evaluation of tender bids will become successful.

\section{APPLICATION OF BDM METHOD TO EVALUATE INFORMATION TECHNOLOGY TENDERS}

The application of BDM method to all the phases of IT tender evaluation process starting from preliminary phase is detailed below.

\subsection{Preliminary phase}

The evaluation process in this phase is to check whether the bidder has satisfied the mandatory requirements of the tender, like paying the EMD amount and continuing in the same line of business. Hence the two issues, namely, EMD payment (X1) and same business line (X2) can be treated as two decision criteria in this phase of evaluation. Following BDM method, if ' 1 ' is assigned to $\mathrm{X} 1$ for positive response, i.e., EMD is paid, ' 0 ' will be assigned to the negative response, i.e., EMD is not paid. In the same way, ' 1 ' is to be assigned to X2, if the bidder is in the same line of business or else ' 0 ' is to be assigned. Assigning bit values in this way forms maximum four possible combinations (A, B, C, D) of input and output values. A truth table, Table 1 , can be developed using these inputs and their result. 
Table 1: Truth table for the Preliminary phase

\begin{tabular}{|c|c|c|c|c|}
\hline \multirow{2}{*}{ Decision Criteria } & \multicolumn{5}{|c|}{ Possible patterns } \\
\cline { 2 - 5 } & A & B & C & D \\
\hline X1 (EMD payment) & 1 & 1 & 0 & 0 \\
\hline $\begin{array}{l}\text { X2 (same business } \\
\text { line) }\end{array}$ & 1 & 0 & 1 & 0 \\
\hline \multicolumn{1}{|c|}{ Output } & 1 & 0 & 0 & 0 \\
\hline
\end{tabular}

The assignment of digits in the above table and the output drawn up will be through application of simple logic by the user. For example, in pattern C, when EMD is not paid means the bidder is not at all eligible to participate in the tender even though the bidder is in the same business line. Hence the output is ' 0 '. Similarly, payment of the EMD alone does not qualify the bidder unless the bidder is in the same business line. This case is represented by pattern B.

From the above possible combinations, the mathematical equation correlating the output $\mathrm{Y} 1$ to the inputs $\mathrm{X} 1$ and $\mathrm{X} 2$, can be generated using Boolean algebra as,

$$
\mathrm{Y} 1=\mathrm{AND}(\mathrm{X} 1, \mathrm{X} 2) \text {. }
$$

In the above equation, simple Boolean 'AND' operation has been used between the two variables, $\mathrm{X} 1$ and $\mathrm{X} 2$; that means $\mathrm{X} 1$. X2.

\subsection{Business Strengths evaluation phase}

In this case, the decision criteria considered are the turnover for the last three financial years, strength of technical staff, and infrastructure availability. For the last three years, the business turnover of each year is to be checked, i.e., whether profit or loss. If it is profit, assign ' 1 ', otherwise, assign ' 0 '. So there are three input criteria elements for the turnover of the last three years $-\mathrm{X} 3, \mathrm{X} 4$, and $\mathrm{X} 5$. Here, a constraint of having profit at least once during the last three financial years may be laid down to consider such bidders. That means, a bidder having no profit at least once during the last three years can be eliminated. For the criterion of strength of technical staff (X6), if it is satisfactory, assign ' 1 ' or else assign ' 0 '. Similar process is followed in the case of infrastructure availability (X7). Thus, Table 2 is the resultant truth table for this phase.

Table 2: Truth table for the Business Strengths phase

\begin{tabular}{|l|r|r|r|r|r|r|r|r|r|r|r|r|}
\hline Decision Criteria & \multicolumn{10}{|c|}{ Possible patterns } \\
\cline { 2 - 12 } & $\mathbf{A}$ & $\mathbf{B}$ & $\mathbf{C}$ & $\mathbf{D}$ & $\mathbf{E}$ & $\mathbf{F}$ & $\mathbf{G}$ & $\mathbf{H}$ & $\mathbf{I}$ & $\mathbf{J}$ & $\mathbf{K}$ & $\mathbf{L}$ \\
\hline X3 (1st year business) & 1 & 1 & 1 & 1 & 1 & 1 & 1 & 1 & 1 & 1 & 1 & 1 \\
\hline
\end{tabular}


International Journal of Managing Public Sector Information and Communication Technologies (IJMPICT) Vol. 5, No. 3, September 2014

\begin{tabular}{|l|r|r|r|r|r|r|r|r|r|r|r|r|}
\hline X4 (2nd year business) & 1 & 1 & 1 & 1 & 1 & 1 & 1 & 1 & 0 & 0 & 0 & 0 \\
\hline X5 (3rd year business) & 1 & 1 & 1 & 1 & 0 & 0 & 0 & 0 & 0 & 0 & 0 & 0 \\
\hline X6 (Technical staff) & 1 & 1 & 0 & 0 & 1 & 1 & 0 & 0 & 1 & 1 & 0 & 0 \\
\hline X7 (Infrastructure) & 1 & 0 & 1 & 0 & 1 & 0 & 1 & 0 & 1 & 0 & 1 & 0 \\
\hline \multicolumn{1}{|c}{ Output } & 1 & 1 & 1 & 0 & 1 & 1 & 1 & 0 & 1 & 0 & 0 & 0 \\
\hline
\end{tabular}

(Constraint: There should be profit at least once during the last three financial years)

The patterns include the bidders having profit in every year, twice and only once during the last three years respectively along with their strengths in manpower and infrastructure. The important constraint used for evaluation regarding turnover is added at bottom of the table.

The way the output is derived is through applying strategy and logic, which may be quite difficult in some cases like patterns, $\mathrm{J}$ and $\mathrm{K}$. There, even though the bidder is having profit at least once during the last three years, the bidder has failed in having either satisfactory strength of technical people or infrastructure, which may not be acquired immediately due to financial losses for the last two years if the bidder is awarded the work. In the case of patterns $F$ and $G$ wherein the bidder is in profit for two years, it is assumed that the bidder is financially capable to strengthen either infrastructure facilities or technical staff. Regarding the pattern I, even though the bidder has profit only once in the last three years, the bidder is having good strengths of technical staff and infrastructure and hence it is assumed that the bidder can wipe out the losses if the work is awarded. Based on the above strategy, the output is assigned a value ' 1 ' for those bidders to be considered. The ultimate correlation equation derived from the truth table is

$$
\begin{array}{r}
\mathrm{Y} 2=\mathrm{OR}(\mathrm{AND}(\mathrm{OR}(\mathrm{AND}(\mathrm{X} 3, \mathrm{X} 4), \mathrm{AND}(\mathrm{X} 4, \mathrm{X} 5), \mathrm{AND}(\mathrm{X} 3, \mathrm{X} 5)), \mathrm{OR}(\mathrm{X} 6, \mathrm{X} 7)), \\
\operatorname{AND}(\mathrm{X} 6, \mathrm{X} 7))
\end{array}
$$

The above Boolean expression is equivalent to [(X3. X4 + X4. X5 + X3. X5). (X6 + X7) + X6 . $\mathrm{X} 7]$.

If the logic and strategy as explained above is changed, the assignment of bit values also changes leading to change in the correlation equation. Hence, it is the duty of decision maker(s) to evolve proper logic and strategy.

\subsection{Technical evaluation phase}

The bidders qualified in the above two phases may be asked to demonstrate their product(s) if the purpose of tender is to purchase product(s), or to develop a prototype application according to the requirements of the user if the purpose of the tender is to develop an application or service. Here, three criteria items may be considered, based on the bidder's capabilities in analysis of user's requirements (X8), development (X9) and presentation (X10). Let us assume to consider a bidder who passes in at least two out of the three evaluation criteria issues $(\mathrm{X} 8, \mathrm{X} 9, \mathrm{X} 10)$. Table 3 is the resultant truth table. 
International Journal of Managing Public Sector Information and Communication Technologies (IJMPICT) Vol. 5, No. 3, September 2014

Table 3: Truth table for the Technical phase

\begin{tabular}{|c|c|c|c|c|c|c|c|c|}
\hline Decision Criteria & \multicolumn{9}{|c|}{ Possible patterns } \\
\cline { 2 - 10 } & A & B & C & D & E & F & G & H \\
\hline X8 (Analysis) & 1 & 0 & 1 & 0 & 1 & 0 & 1 & 0 \\
\hline X9 (Development) & 0 & 0 & 1 & 1 & 1 & 1 & 0 & 0 \\
\hline X10 (Presentation) & 1 & 1 & 0 & 0 & 1 & 1 & 0 & 0 \\
\hline Output & 1 & 0 & 1 & 0 & 1 & 1 & 0 & 0 \\
\hline
\end{tabular}

The equation correlating the output to the inputs is as follows,

$$
\mathrm{Y} 3=\mathrm{OR}(\mathrm{AND}(\mathrm{X} 8, \mathrm{OR}(\mathrm{X} 9, \mathrm{X} 10)), \mathrm{AND}(\mathrm{X} 9, \mathrm{X} 10))
$$

The above Boolean expression is similar to $[\mathrm{X} 8 .(\mathrm{X} 9+\mathrm{X} 10)+\mathrm{X} 9 . \mathrm{X} 10$.

\subsection{Financial Quotation evaluation phase}

The bidders who get through successfully from the third phase of evaluation will be invited to attend the event of opening of their financial bids. After opening the financial bids, the rates quoted by different bidders are displayed to start further evaluation exercise. This phase of evaluation includes checking the price quoted (X11) by the bidder for the product or service and testing the bidder's flexibility for negotiations on price or services (X12). From the list of prices, if the price quoted by a bidder is considerably high, ' 0 ' is to be assigned to the criteria item, X11, or if the price quoted is reasonable or considerably low , ' 1 ' is to be assigned to X11. If the bidder is ready for negotiations, 1 is to be assigned to the variable, X12, and 0 otherwise. Let us assume that even though a bidder quotes high price, the bidder can be considered on the grounds of flexibility for negotiations. Following this strategy, Table 4 will be the resultant truth table.

Table 4. Truth table for the Financial quotes phase

\begin{tabular}{|c|c|c|c|c|}
\hline \multirow{2}{*}{ Criteria item } & \multicolumn{4}{|c|}{ Possible patterns } \\
\cline { 2 - 5 } & A & B & C & D \\
\hline X11 (quoted price) & 1 & 1 & 0 & 0 \\
\hline X12 (flexibility for negotiations) & 1 & 0 & 1 & 0 \\
\hline Output & 1 & 1 & 1 & 0 \\
\hline
\end{tabular}

From the possible combinations of inputs and outputs as shown in the table, the resultant correlation equation is

$$
\mathrm{Y} 4=\mathrm{OR}(\mathrm{X} 11, \mathrm{AND}(\mathrm{NOT}(\mathrm{X} 11), \mathrm{X} 12))
$$


The above Boolean expression is similar to [X11 + X11. X12].

\subsection{Final evaluation phase}

This is a critical phase because of finalizing the successful one from the competing bidders and for this purpose the decision maker(s) may evolve their own strategy or use a general strategy. The decision maker may also combine the results of both third (technical) and fourth (financial) phases of evaluation to take a consolidated decision. For example, the customer may pick up the bidders who have scored ' 1 ' for all the criteria items under the technical phase and check whether they have passed in the financial phase. If more bidders are found passed in this way, the bidders who have scored ' 1 ' for the two criteria items in the financial phase can be considered. Even then, if a number of competing bidders are resulted, a bidder can be finally selected based on the negotiations held on price and services.

A simple Microsoft Excel spreadsheet has been developed to validate all the Boolean algebraic expressions presented in the form a mathematical models. The results are exactly coinciding with the results obtained through application of administrative analogy and the organizational policies and procedures. This case is an application to show how a complex decision system can be divided among different phases of decision making process and appropriate mathematical models using Boolean algebra can be developed by covering the contribution of various salient variables that influence the system at different stages.

The Microsoft Excel spreadsheet developed to implement the BDM method is shown in the figure, Figure 2.

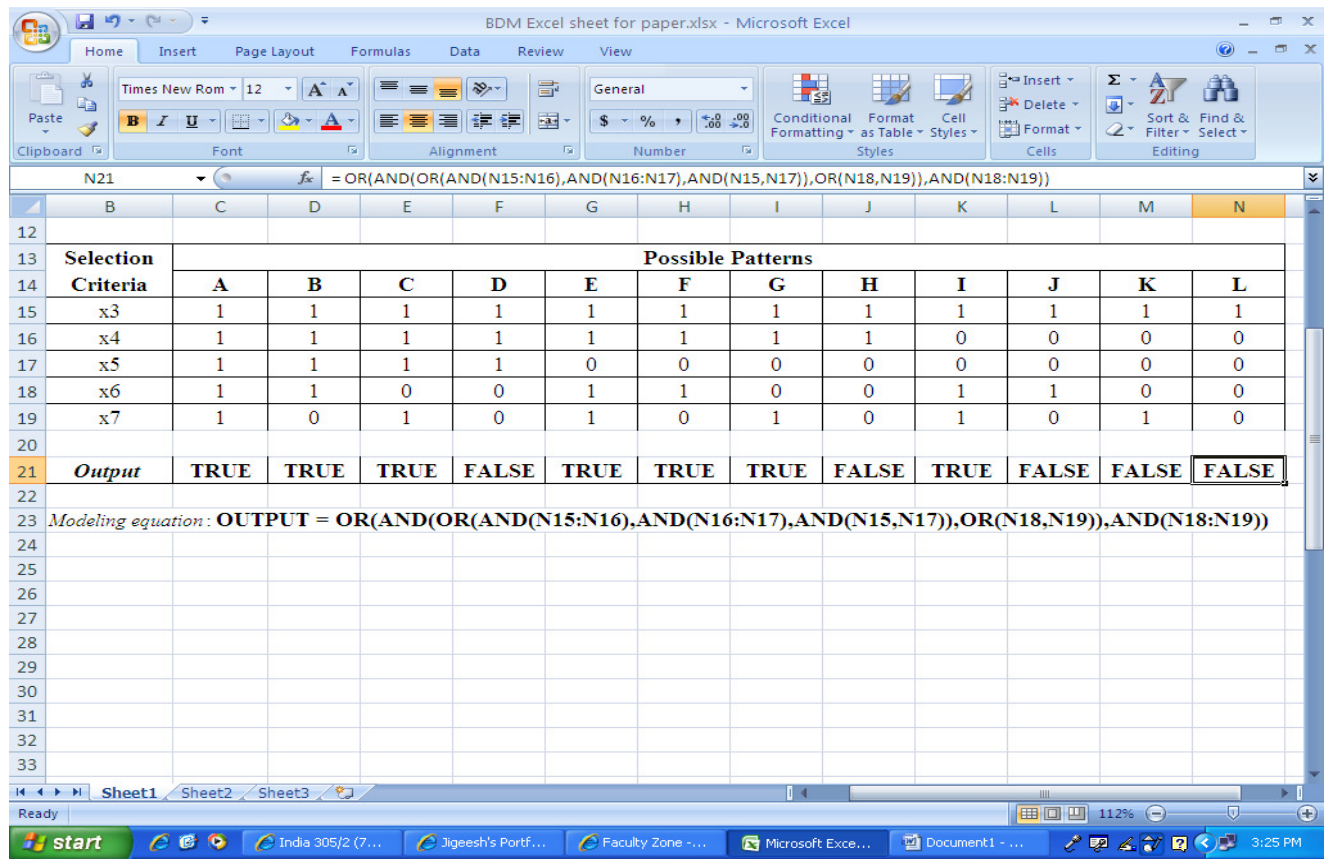

Figure 2. Spreadsheet showing application of BDM method for making decision 


\section{FEATURES OF BDM METHOD}

From the theory and methodology and results of application of BDM method, the following features of the method have been summarized:

Granularity: In BDM method, a complex system can be divided into a reasonable number of independent, meaningful and manageable sub-systems or phases to ease the decision making process. The size of the resulting grain of the system will be decided by the concerned decision maker(s) and their implementation of logic and strategy.

Flexibility: Based on the decision criteria useful for making decisions in each phase, possible patterns of combination of input values and the ultimate output value are created. The patterns with the same input values need not result the same output value in different phases. This is due to the difference in using specific logic, strategy and analogy in different phases. This is evident from the truth tables, Table 1 and Table 4, wherein the same input patterns are present but with different outputs. In addition to the changes in the logic and values of the inputs and outputs, the correlation equation will also change accordingly. This way, the BDM method provides a lot of flexibility to change decision criteria, their values and the ultimate output values depending upon the strategy and logic the user wants to implement in a particular evaluation phase.

Standardization: Once the equations correlating the inputs to the output are derived for each subsystem, they will act as evaluation-model standards to automate the decision making process. Any change in either the criteria items or their resultant output value in any sub-system leads to change the mathematical correlation equation of that sub-system. A sub-system with a fixed mathematical model can be treated as a standardized decision system, which automates the decision process with any number of cases. This way of standardizing decision making in each sub-system leads to the formulation of a standard decision making system for the whole complex system.

Integration: Once the whole process is described along with different phases and their sequence, the output pertaining to an entity in one phase decides whether to go it to next phase or not. The entities that pass one phase will move to next phase and this continuity will be maintained till the last phase. Last phase deals with those entities that successfully passed all the phases and decides the best one out of them.

Linear programming methods help the organizations to have optimization solution with a set of most-feasible values for the variables under consideration subject to the given constraints. This is one time solution for a problem of selected variables and constraints. In the case of AHP, it starts with a problem, identify subsequent criteria and sub-criteria at different levels and work with their data for each pair of alternatives available. Let us take the same problem of selection of a bidder from a set of bidders who submitted the bids. To select the bidder, in AHP, there will be some criteria established by the organization, for example, price, service, reputation, expertise, etc. Under each criteria, there may be different sub-criteria items and so on, depending upon the attributes of processes and participants. The bidders will be treated as alternatives and the scores will be awarded to each criteria and subsequent sub-criteria by pair-wise comparisons of alternative bidders. Even though the BDM method is also a phased approach like AHP, it concerns with the criteria items related to a particular phase based on the policies and procedures of the organization. The movement to other phase will be possible once the current phase has been completed and the alternatives are filtered out. This is just like a system development life cycle (SDLC) or simply the water-fall method. 


\section{CONCLUSIONS}

There are systems where a firm decision, i.e., either 'yes' or 'no' is to be taken for each criteria issue present therein and there will not be any scope for weighing the item in between those extreme decision points, just like in fuzzy logic systems. The number of such decision criteria varies differently in different systems and in big and complex systems there may be large number of such criteria. The method (BDM) presented in this paper assumes that a complex system can be divided into a reasonable number of independent, meaningful and manageable sub-systems or phases arranged in sequence to ease the decision making process. The BDM method has many important features like granularity, flexibility, standardization, and integration. It uses Boolean logic and simple Boolean operations ('OR', AND, and NOT) and derives mathematical model for each sub-system. The system with a specific mathematical model can be treated as a standardized decision system and any changes made in either the decision criteria or their resultant output lead to change in the mathematical model. A real world case study, the evaluation of IT tenders in one public-sector company, is given as an example of application of BDM method so as to provide a wide scope for the method to be applied to other areas and other fields to simplify the complex decision process. The same method can be applied to evaluate the performance of the selected suppliers in performing their assigned supply tasks from time to time in different dimensions like quality, cost, delivery/shipping and reduction of cycle time, etc. Following this method, a Microsoft Excel spreadsheet can be created as a decision support system to feed the Boolean values for each and every evaluation criterion and get the decisionresult for each entity and for that whole system automatically.

\section{REFERENCES}

[1] Baker, D., Bridges, D., Hunter, R., Johnson, G., Krupa, J., Murphy, J. \& Sorenson, K. (2001) "Guidebook to Decision-Making Methods", Department of Energy, USA. Retrieved on May 20, 2006, http://emi-web.inel.gov/Nissmg/Guidebook_2002.pdf.

[2] Braglia, M. \& Petroni, A. (2000) "A quality-assurance oriented methodology for handling tradeoffs in supplier selection”, International Journal of Physical Distribution \& Logistics, Vol. 30, No. 2, pp 96-111.

[3] Choi, T.Y. \& Hartley, J.L. (1996) "An exploration of supplier selection practices across the supply chain”, Journal of Operations Management, Vol. 14, pp 333-343.

[4] Choy, K.L., Lee, W.B., \& Lo, V. (2002) "An intelligent supplier management tool for benchmarking suppliers in outsource manufacturing”, Expert Systems with Applications, Vol. 22: 213-224.

[5] Clemen, R. T. (1996) "Making Hard Decisions; an Introduction to Decision Analysis", Brooks/Cole, CA : Pacific Grove.

[6] Dahel, N.E. (2003) "Vendor selection and order quantity allocation in volume discount environments", Supply Chain Management: An International Journal, Vol. 8, No. 4, pp 334-342.

[7] De Boer, L., Wegen, L., \& Telgen, J. (1998) "Outranking methods in support of supplier selection", European Journal of Purchasing \& Supply Management, Vol. 7, pp 109-118.

[8] Edwards, W. \& Barron, F. H. (1994). "SMARTs and SMARTER; Improved Simple Methods for Multiattribute Utility Measurement", Organizational Behaviour and human Decision Processes. Vol. 60, pp 306-325.

[9] Folger, H.S. \& LeBlanc, S.L. (1995) "Strategies for Creative Problem Solving", Upper Saddle River, New Jersey: Prince-Hall.

[10] France, L.B., John, S. \& Mary, S. \& Courtland, S (2002) "Development and evaluation of multiple-objective decision-making methods for watershed management planning”, Journal of the American Water Resources Association, Vol. 38, No. 2, pp 517-530.

[11] Fraser, J. (1995) "Professional Project Proposals", Aldershot, UK : Gower/Ashgate.

[12] Ghodsypour, S.H. \& O’Brien, C. (1998) “A decision support system for supplier selection using an integrated analytic hierarchy process and linear programming", International Journal of Production Economics, Vol. 56/57, pp 199-212. 
International Journal of Managing Public Sector Information and Communication Technologies (IJMPICT) Vol. 5, No. 3, September 2014

[13] Goodwin, P. \& Wright, G. (1998) "Decision Analysis for Management Judgment", New York : Wiley.

[14] Gray, C. F. \& Larson, E. W. (2003) "Project Management - The managerial process", New York: McGraw-Hill.

[15] Hammond, J., Keeney, R. \&d Raiffa, H. (1999) "Smart Choices, A Practical Guide to Making Better Decisions", Boston: Harvard Business School Press.

[16] Harris, R. (2006) "Decision Making Techniques", Retrieved on May 22, 2006, http://www.virtualsalt.com/crebook6.htm.

[17] Hillier, F. S. \& Lieberman, G. J. (2001) "Introduction to Operations Research", 7th edition, Singapore : McGraw Hill.

[18] Hooks, I.F. (1994) "Guide for Managing and Writing Requirements", Houston, TX : Compliance Automation, Inc.

[19] Kepner, C. H. \& Tregoe, B. B. (1981) “The New Rational Manager", Princeton, NJ : Princeton Research Press.

[20] Miah, S. J. \& Huth, M. (2011) "Cross-functional decision support systems for supplier selection problem", International Journal of Management and Decision Making, Vol. 11, No. 3/4, pp 217230.

[21] Min, H. (1994) "International supplier selection: a multi-attribute utility approach", International Journal of Physical Distribution \& Logistics Management, Vol. 24, No. 5, pp 24-33.

[22] Paulus, S. and Riemann, U. (2013) "An approach for a business-driven cloud-compliance analysis covering public sector process improvement requirements", International Journal of Managing Public Sector Information and Communication Technologies (IJMPICT), Vol. 4, No. 3.

[23] Saaty, T. L. (1990) "Multicriteria Decision Making : The Analytic Hierarchy Process", AHP Series, Vol. 1, Pittsburgh : RWS Publications.

[24] Saaty, T. L. (1995) "Decision Making for Leaders : The Analytic Hierarchy Process for Decisions in a complex world", Pittsburgh : RWS Publications.

[25] Saaty, T. L. \& Kearns, K. P. (1985) “Analytical Planning”, Pittsburgh : RWS Publications.

[26] Sharma, R. K. Gaur, A. \& Okunbor, D. (2004) "Management decision-making for transportation problems through goal programming", Journal of the Academy of Business and Economics, Vol. 4, No. 1, p. 195.

[27] Simon, H. A. \& Associates (1986) "Report on the Research Briefing Panel on Decision Making and Problem Solving", Washington, DC : National Academy Press. Retrieved May 20, 2006, http://dieoff.org/page163.htm.

[28] Yang, Ching-Chow, \& Chen, Bai-Sheng (2006) "Supplier selection using combined analytical hierarchy process and grey relational analysis", Journal of Manufacturing Technology Management, Vol. 17, No. 7, pp 926-941.

\section{Author: Dr. Nasina Jigeesh}

Dr. N.Jigeesh, Ph.D (Physics), Ph.D. (Management Science) working as a Professor \& Head of the Department of Operations \& Systems, IBS-Hyderabad, which is a constituent of the ICFAI Foundation for Higher Education (IFHE) University. He has above 25 years of experience in both Industry and Academia. His experience includes Administration, Management, Teaching and Research. Published several papers in both International and National Journals and in Conferences as well. Teaching the subjects of Project Management, Information Systems for Managers, Enterprise-wide Systems for Managers, DBMS, Data

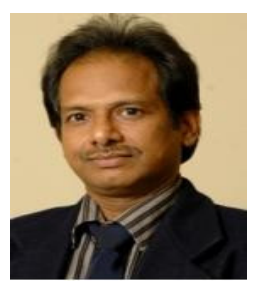
Mining \& Data Warehousing, e-Business, Business Intelligence \& Business Analytics. He guided one Ph.D. work and is guiding several other Ph.D. students in the area of Mangement Science. His research interests include Project Management, Knowledge Management and Information Technology/Systems. 